\title{
Aspectos da Fenologia e Ecologia de Hedychium coronarium (ZINGIBERACEAE) NA EstaÇÃo ECOLÓGICA do TRIPUí, OURO PRETO-MG ${ }^{1}$
}

\author{
Phenological and Ecological Aspects of Hedychium coronarium (Zingiberaceae) at the Tripuí \\ Ecological Station, Ouro Preto-MG
}

SANTOS, S.B. ${ }^{2}$, PEDRALLI, G. ${ }^{\dagger 3}$ e MEYER, S.T. ${ }^{4}$

\begin{abstract}
RESUMO - Hedychium coronarium é uma macrófita aquática considerada exótica e invasora fora da região do Himalaia, seu centro dispersor. Introduzida nas Américas, ocorre em diversas regiões do Brasil, inclusive na Estação Ecológica do Tripuí (EET), Ouro Preto-MG. As macrófitas invasoras ocasionam efeitos negativos sobre a biodiversidade regional e, portanto, requerem estudos sobre sua fenologia e ecologia como subsídio para medidas de controle e manejo. Aspectos relacionados a crescimento em altura, floração, frutificação e duração das hastes foram avaliados entre agosto de 2002 e julho de 2003 em diferentes áreas da EET. Áreas com sombreamento entre 60 e 80\% apresentam maior crescimento em altura e melhor frutificação, merecendo, por isso, maior atenção para o manejo e controle.
\end{abstract}

Palavras-chave: exótica invasora, macrófita aquática, biodiversidade, manejo e controle.

\begin{abstract}
Hedychium coronarium is an aquatic macrophyte considered an alien and invasive plant outside the Himalayan region, its dispersal center. It was introduced in the Americas, occurring in different regions in Brazil, including the Tripui Ecological Station (EET) in Ouro Preto-MG. This plant has negative effects on regional biodiversity, thereby studies on its phenological and ecological aspects are needed to assist in control and management measures. Aspects such as height growth, flowering, fructification and stem duration were evaluated between August 2002 and July 2003 at different EET areas. Areas with shade between 60-80\% allowed better height growth and fructification. These areas require more attention in management and control.
\end{abstract}

Key words: invasive alien, aquatic macrophyte, biodiversity, management and control.

\section{INTRODUÇÃO}

Desde a criação do termo macrófitas aquáticas em 1938 o conceito desses vegetais foi sendo moldado por alguns autores, como Cook (1974) e Irgang \& Gastal (1996). De acordo com o primeiro autor, as plantas aquáticas são todos os vegetais desde "Charophyta, Bryophyta, Pteridophyta e Spermatophyta cujas partes fotossinteticamente ativas estão permanentemente ou por alguns meses em cada ano submersas no corpo d'água ou flutuantes na superfície d'água". Irgang \& Gastal (1996), com base no conceito de Cook (1974), incluem as plantas de ambientes salobros e marinhos à definição.

De modo amplo, as macrófitas aquáticas ocorrem em zonas úmidas (Pedralli, 2003; Pedralli \& Teixeira, 2003), como definido pela Convenção Ramsar (1971). Hedychium coronarium (lírio-do-brejo) é uma macrófita

Recebido para publicação em 23.12.2004 e na forma revisada em 1.4.2005.

2 Mestranda em Ecologia Vegetal pela UFPR, <sayonarabsantos@yahoo.com.br>; ${ }^{3 \dagger}$ Doutor em Biologia Vegetal, Prof. UFOP, CETEC. ${ }^{4}$ Mestre em Biologia Vegetal do CETEC, <Sylvia.Meyer@cetec.br>. 
aquática nativa da região do Himalaia, na Ásia tropical (Macedo, 1997; Pio Corrêa, 1984). Ocorre nas Américas, como introduzida, desde os Estados Unidos até a Argentina (Kissmann $\&$ Groth, 1991). No Brasil, a espécie é muito comum em toda a zona litorânea (Kissmann \& Groth, 1991); em Minas Gerais, ela é citada em várias regiões (Cruz, 2002; Macedo, 1997; Pedralli \& Meyer, 1996; Ferreira \& Pedralli, 2002).

Em regiões de importante diversidade biológica, são necessários estudos relacionados à biologia e ecologia de espécies invasoras, sobretudo em conseqüência dos reflexos negativos que estas plantas podem ocasionar sobre a biodiversidade local e regional (Pitelli, 1998; Pedralli, 2001; Ramsar, 2004). As conseqüências negativas sobre as espécies nativas tornam estas plantas daninhas nos locais onde proliferam.

$\mathrm{O}$ fato de $H$. coronarium ter sido encontrada na região de Ouro Preto (Cruz, 2002; Ferreira \& Pedralli, 2002; FEAM, 1995), área prioritária de acordo com o Programa Nacional de Diversidade Biológica (Pronabio) do Ministério do Meio Ambiente (2003), ressalta a importância do estudo e monitoramento dessa espécie.

Além desse fato, estudos que permitem conhecer as adaptações e o crescimento do lírio-do-brejo, como maneira de obter seu manejo e controle no âmbito da Estação Ecológica do Tripuí - EET (Cruz, 2002; FEAM, 1995), atendem ao interesse do Plano de Manejo da Estação (FEAM, 1995).

Dessa forma, os objetivos do presente trabalho foram acompanhar e registrar os eventos relacionados aos aspectos fenológicos e biológicos no período de um ano, bem como analisar a influência dos fatores temperatura e precipitação média mensais no crescimento em altura das partes aéreas, visando subsidiar estratégias de manejo da espécie.

\section{MATERIAL E MÉTODOS}

\section{A espécie em estudo}

A palavra Hedychium vem do grego e significa 'neve doce'. A palavra coronarium, do latim 'corona', significa 'coroa' (Kissmann \& Groth, 1991). Hedychium coronarium recebe os nomes comuns de lírio-do-brejo, mariazinha-do-brejo e gengibre-branco (Kissmann \& Groth, 1991; Macedo, 1997). Trata-se de uma monocotiledônea da família Zingiberaceae, rizomatosa, de hábito herbáceo perene.

O lírio-do-brejo apresenta parte aérea organizada em caule simples cilindrico, avermelhado na base, folhas lanceoladas de distribuição alternada (Kissmann \& Groth, 1991), inflorescência em espiga, com brácteas imbricadas, flores com corolas brancas ou amarelopálidas e estaminódios petalóides (Kissmann \& Groth, 1991; Macedo, 1997). A espécie apresenta tanto a reprodução sexuada, por formação de sementes, quanto a assexuada, pela produção de hastes aéreas a partir do rizoma (Tunison, 1991; Stone et al., 1992). Os polinizadores noturnos são as mariposas, em virtude da coloração branca e do aroma atrativo das flores (Endress, 1994).

Segundo Tunison (1991), fragmentos dos rizomas podem se dispersar pela água, através das bacias hidrográficas, e apresentar crescimento vegetativo em novas áreas. Os frutos maduros apresentam cor alaranjada, que contrasta com a cor vermelha do arilo das sementes (Kissmann \& Groth, 1991). O desenvolvimento das sementes aparentemente depende do fator distribuição geográfica e altitude (Tunison, 1991; Stone et al., 1992).

\section{Localização da área}

A Estação Ecológica do Tripuí é uma Unidade de Conservação (UC) situada a SE do Quadrilátero Ferrifero (Cruz, 2002), no município de Ouro Preto, MG. Localiza-se entre os meridianos de $43^{\circ} 34^{\prime} 33^{\prime \prime}$ de longitude $\mathrm{W}$ e os paralelos de $20^{\circ} 23^{\prime} 45^{\prime \prime}$ de latitude S. Possui níveis altimétricos variando entre $1.100 \mathrm{e}$ 1.450 metros (FEAM, 1995). O domínio climático é do tipo Cwb, segundo Köppen, caracterizado por precipitações abundantes no verão. A EET atinge, de acordo com observações locais, indices de temperaturas inferiores a $0^{\circ} \mathrm{C}$, com ocorrência de geada (FEAM, 1995).

A Estação está situada em área de transição entre Floresta Atlântica e Cerrado (Rizzini, 1997; Fernandes \& Bezerra, 1990; Ab’Saber, 1977). Sua cobertura vegetal, de modo geral, apresenta várias fisionomias vegetais. É composta por florestas estacionais semideciduais, 
campos limpos e campos sujos de cerrado. Além dessas formações, existem áreas de brejos permanentes, com sua vegetação característica, e áreas cultivadas (FEAM, 1995).

\section{Método de estudo}

Em cada área amostral selecionada foram devidamente enumerados 15 indivíduos de $H$. coronarium na fase inicial de desenvolvimento. Foram estabelecidas cinco áreas com quantidades variáveis de espécies arbóreas e arbustivas, as quais proporcionavam diferentes percentuais de sombreamentos, observados visualmente entre 11 e 14 horas em dias de sol (Carvalho et al., 2002; Silva \& Nääs, 1996; Wong, 1991).

Os indivíduos na área 1 apresentavam-se sob sombreamento de 0 a $10 \%$, com poucas espécies arbóreas distribuídas pela população de lírio-do-brejo. Na área 2, os lírios-do-brejo mantiveram-se sob sombreamento arbóreo e arbustivo de 60 a $80 \%$. Durante todo o ano a área apresentou acúmulo de água no solo e, no período chuvoso, formação de pequenos cursos d'água. As plantas na área 3 mantiveram-se entre 0 e $30 \%$ de sombreamento em área de sucessão secundária. Nesta área, as espécies arbóreas apresentam-se esparsamente distribuídas entre os indivíduos de lírio-do-brejo.

Os indivíduos da área 4 situavam-se numa região de clareira ocasionada por uma pequena barragem, dentro de um fragmento de floresta estacional semidecidual. O sombreamento variou entre 60 e 95\% . A área 5 apresentou topografias diferenciadas. Num local da área os lírios-do-brejo localizavam-se em solo plano com sombreamento de $80 \%$ e, em outro local, o desnivel do terreno proporcionou sombreamento de $30 \%$.

As plantas foram selecionadas com distância mínima de 1,0 a $1,5 \mathrm{~m}$ e ausência de sinais de floração e frutificação, admitindo-as como indivíduos únicos. A partir desses indivíduos foram tomadas as medidas de altura e observadas as fenofases. Realizaram-se as medições mensais de altura $(\mathrm{H})$ em 45 indivíduos no total, sendo nove de cada área amostral. As médias foram obtidas mensalmente, entre novembro de 2002 e abril de 2003, em seis meses consecutivos.
As fenofases acompanhadas foram a floração, a frutificação e a duração das partes aéreas (Fournier \& Charpantier, 1995; Morellato et al., 1989; Morellato \& Bencke, 2002). O acompanhamento das fenofases foi realizado em 69 indivíduos entre agosto de 2002 e julho de 2003, atendendo ao mínimo de cinco indivíduos em cada área, recomendado por Fournier \& Charpantier (1995).

A observação do horário da antese aconteceu durante o período de 24 horas, de hora em hora, em dois dias não-consecutivos (7/2 e 29/3/03), em duas áreas. A partir da abertura dos botões, as observações foram realizadas de 30 em 30 minutos, durante dez minutos.

Para as variações morfológicas dos frutos foi adotada uma simbologia própria: o símbolo de sinal negativo (-) foi atribuído aos frutos totalmente malformados, cujas sementes apresentavam-se todas escuras e enrugadas; e o sinal positivo e negativo $(+/)$ foi conferido aos frutos malformados que apresentavam pelo menos uma semente em aparente bom estado. Já o sinal positivo (+) foi atribuído aos frutos com sementes vermelhas e vistosas.

O tempo de duração e a determinação dos meses de morte completa das partes aéreas foram estabelecidos acompanhando-se mensalmente os aspectos visuais do incremento de folhas e do processo gradativo da senescência foliar/caulinar.

Neste trabalho adotou-se o termo população com o sentido de amostras populacionais, pois as áreas de estudo localizam-se próximas entre si, de maneira que os indivíduos amostrados possivelmente pertencem a uma única população.

Os dados climáticos de temperaturas médias mensais foram obtidos diretamente do Instituto Nacional de Pesquisas Espaciais (www.cptec.inpe.br) e de precipitações médias mensais da Empresa de Alumínio Canadense do Brasil (ALCAN), em Ouro Preto.

\section{Análise dos dados}

Os aspectos fenológicos floração e frutificação foram avaliados por meio do Índice de Atividade - IA (Morellato \& Bencke, 2002), nas respectivas áreas amostrais.

Planta Daninha, Viçosa-MG, v. 23, n. 2, p. 175-180, 2005 


$$
\mathrm{IA}=\frac{\mathrm{N}^{\circ} \text { indivíduos apresentando fenofase }}{\mathrm{N}^{\circ} \text { de indivíduos acompanhado }} \times 100
$$

\section{RESULTADOS e DISCUSSÃO}

\section{Crescimento}

A diferença do crescimento médio em altura entre áreas amostrais possivelmente variou de acordo com o sombreamento da área estudada (Figura 1). No mês de maiores médias de alturas, em fevereiro de 2003, o maior valor das cinco áreas correspondeu a 181,4 cm na área 2, e o menor, a $117,1 \mathrm{~cm}$ na área 1 . Possivelmente, o baixo crescimento médio em altura possa estar relacionado com o baixo sombreamento (0 a 10\%) da área 1, cuja exposição solar foi maior.

$\mathrm{Na}$ área 1 , a exposição elevada às variações diárias, inclusive a geadas, ocasionou enrugamento das folhas superiores em março e abril/03 e morte dos indivíduos entre maio e junho/03. A aparente queda no crescimento das plantas da área 1 evidenciada pela Figura 1, nos meses de março e abril/03, é conseqüência do enrugamento da folhagem superior.

O sombreamento proporcionado por árvores e arbustos mais homogeneamente distribuídos (área 2) ou distribuídos em uma margem da área (áreas 3 e 5) ocasionou maior crescimento em altura dos indivíduos de $H$. coronarium sob influência das copas. Entretanto, na área 4, as plantas da espécie $H$. coronarium que estavam constantemente sob sombreamento não apresentaram alturas significativas. Apenas as plantas situadas em volta da clareira evidenciaram maiores alturas e produção de inflorescências.

$\mathrm{Na}$ população total amostrada de $H$. coronarium, observou-se o incremento na altura quando a temperatura e precipitação atingiram valores elevados no verão, entre novembro/02 e fevereiro/03 (Figura 2). A partir de fevereiro/03, com a diminuição de temperatura e de precipitação, os indivíduos amostrados mantiveram as médias de altura. As partes aéreas apresentaram duração de aproximadamente 11 meses (agosto/02 a junho/ 03). Em julho/03, todas as áreas, com exceção de algumas plantas da área 4, apresentavam todos os indivíduos com suas hastes mortas. A morte das hastes na área 1 ocorreu de forma antecipada em relação à maioria das plantas nas outras amostras.

\section{Fenologia}

A fenofase floração apresentou maior porcentagem do número de individuos floridos em fevereiro/03, com 27,54\% (Figura 3). A população mostrou alta sincronia, com período de floração entre janeiro e março/03. A altura mínima dos indivíduos floridos foi de $102 \mathrm{~cm}$, na área 1. A altura máxima dos indivíduos com inflorescência foi de $240 \mathrm{~cm}$, na área 2. A antese das flores ocorreu no periodo da tarde, entre $12 \mathrm{~h} 45$ e $17 \mathrm{~h} 15$.

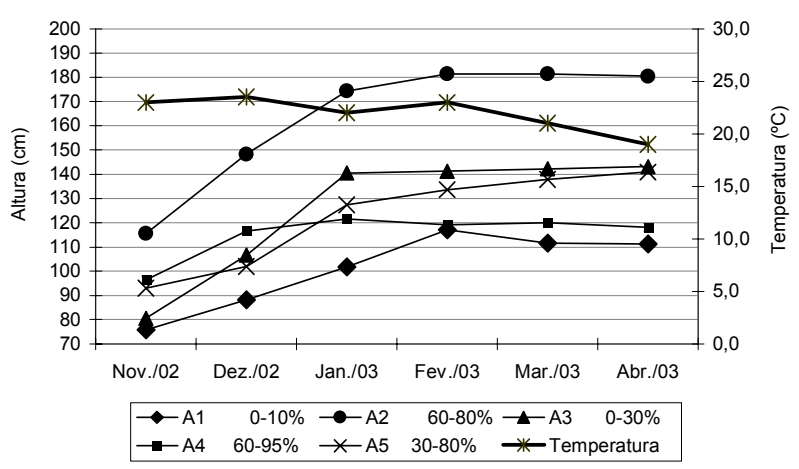

Figura 1 - Alturas médias mensais (nov./02 a abr./03) de Hedychium coronarium em cada área amostrada na EET/ OP, Ouro Preto-MG.

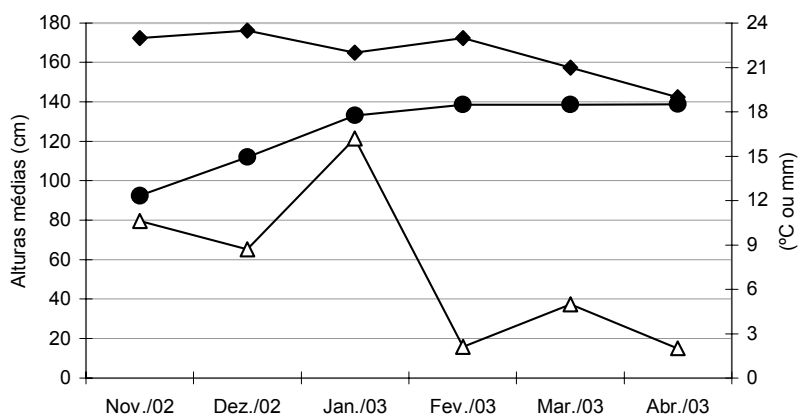

Figura 2 - Alturas médias mensais da população de H. coronarium em (- - na EET/OP, MG e as variações da temperatura média da região $\left({ }^{\circ} \mathrm{C}\right)$ em $(-\downarrow)$ e de precipitação média $(\mathrm{mm})$ em $(-\Delta-)$ entre novembro/02 e abril/03. 


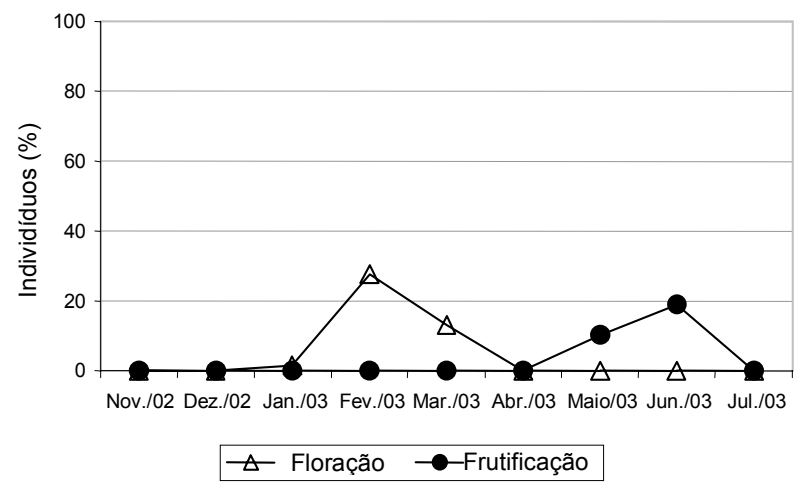

Figura 3 - Atividade das fenofases floração e frutificação na população de lírio-do-brejo amostrada na EET/OP, Ouro Preto-MG.

O percentual de indivíduos em que houve frutificação foi de $29,0 \%$ do total observado, considerando apenas frutos na categoria (+/-) e (+). Essa fenofase também mostra grande sincronismo, com pico, em junho/03, de $18,84 \%$ (Figura 3). Os indivíduos que não apresentaram frutos viáveis localizavam-se nas áreas 1,3 e 4 . As áreas 1 e 3 apresentaram indivíduos expostos à luminosidade, pela ausência ou pouca freqüência de árvores e/ou arbustos entre os lírios-do-brejo. Entretanto, muitos indivíduos na área 4 apresentaram-se com maior percentual de sombreamento: 60 a $95 \%$.

A variação na formação das sementes e dos frutos viáveis pode estar relacionada a condições ambientais de sombreamento nas áreas, diferentemente da possibilidade relatada, para $H$. coronarium, de variações na formação das sementes de acordo com as localizações altitudinais (Tunison, 1991; Stone et al., 1992). Tanto o excesso de luminosidade quanto o de sombreamento podem limitar e influenciar o crescimento, a floração e frutificação.

Na Estação Ecológica do Tripuí, a área 2 apresentou maior crescimento e maior número de frutos viáveis. As características marcantes apresentadas nesta área foram o sombreamento intermediário (60 a $80 \%$ ) e a presença de poças de água, proporcionando umidade aos indivíduos. A constatação de características ambientais que propiciaram o melhor desenvolvimento do lírio-do-brejo é um elemento importante para subsidiar planos de manejo e controle da espécie.
Dessa forma, sugere-se que o controle por meio de poda deve ser aplicado principalmente entre os meses de dezembro e janeiro, antes dos picos de floração e frutificação e antes que os indivíduos adquiram aproximadamente $102 \mathrm{~cm}$ de altura.

A retirada dos rizomas seria adequada no período de inverno para evitar a propagação de seus fragmentos por veiculação hídrica. Considerando-se as áreas ocupadas por $H$. coronarium na EET e as observações realizadas no período deste trabalho, a espécie apresenta expansão representativa na Estação, com a presença das fenofases floração e frutificação.

As áreas que oferecem maior retenção de umidade e sombreamento (entre aproximadamente 60 e $80 \%$ ) merecem atenção especial, em razão do maior desenvolvimento dos indivíduos e da formação de frutos viáveis.

Novos estudos na área que tratem do processo inicial de colonização e do crescimento e regeneração do rizoma podem proporcionar efetividade no manejo e controle, bem como no monitoramento de expansão e/ou retração de $H$. coronarium, das áreas ocupadas na EET.

\section{AGRADECIMENTOS}

Ao professor Dr. Gilberto Pedralli†, que não pôde acompanhar a publicação deste trabalho.

\section{LITERATURA CITADA}

AB' SABER, A. N. Os domínios morfoclimáticos da América do Sul. B. Inst. Geog. USP, v. 52, p. 1-21, 1977.

BRASIL. Ministério do Meio Ambiente. Biodiversidade brasileira: avaliação e identificação de áreas e ações prioritárias para conservação, utilização sustentável e repartição dos benefícios da biodiversidade nos biomas brasileiros. Brasília: Secretaria de Biodiversidade e Florestas, 2003. p. 215-265.

CARVALHO, M. M.; FREITAS, V. P.; XAVIER, D. F. Início de florescimento, produção e valor nutritivo de gramíneas forrageiras tropicais sob condições de sombreamento natural. Pesq. Agropec. Bras., v. 37, n. 5, p. $717-722,2002$.

COOK, C. D. K. Water plants of the world. The Hague, Junk B.V., 1974. p. 1-555.

Planta Daninha, Viçosa-MG, v. 23, n. 2, p. 175-180, 2005 
CRUZ, L. V. Avaliação geoquímica ambiental da Estação Ecológica do Tripuí e adjacências, sudeste do quadrilátero ferrífero, MG. 2002. 147 f. Dissertação (Mestrado em Geoquímica Ambiental) - Universidade Federal de Ouro Preto, Ouro Preto, MG, 2002.

ENDRESS, P. K. Diversity and evolutionary biology of tropical flowers. Cambridge: University Press, 1994. p. $358-365$.

FUNDAÇÃO ESTADUAL DO MEIO AMBIENTE FEAM. Plano de Manejo da Estação Ecológica do Tripuí, Ouro Preto, MG. Belo Horizonte: 1995. v. 1.

FERNANDES, A.; BEZERRA, P. Estudo fitogeográfico do Brasil. Fortaleza: Stylos Comunicações, 1990. 205 p.

FERREIRA, F. A.; PEDRALLI, G. Florística, diversidade e aspectos ecológicos das macrófitas aquáticas em dois trechos de $1^{\mathrm{a}}$ ordem dos córregos da Lapa e do Tripuí, Ouro Preto, M.G. CONGRESSO NACIONAL DE BOTÂNICA, 53., 2002, Recife. Resumos... Recife: SBB/UFPE, 2002. p. 346.

FOURNIER O, L. A.; CHARPANTIER, C. El tamanõ de la muestra y la frecuencia de las observaciones en el estudio de las características fenológicas de los árboles tropicales.

Turrialba, v. 25, n. 1, p. 45-48, 1995.

IRGANG, B. E.; GASTAL, C. V. S. Macrófitas aquáticas da planície costeira do Rio Grande do Sul. Porto Alegre: 1996. p. 9-20.

KISSMANN, K. G; GROTH, D. Plantas infestantes e nocivas. São Paulo: Basf Brasileira, 1991. p. 590-593.

MACEDO, J. F. O gênero Hedychium koening (Zingiberaceae) no Estado de Minas Gerais. Daphne, v. 7 , n. 2, p. 27-31, 1997.

MORELLATO, L. P. C. et al. Estudo comparativo da fenologia de espécies arbóreas de floresta de altitude e floresta mesófila semidecídua na Serra do Japi, Jundiaí, São Paulo. R. Bras. Bot., v. 12, p. 85-98, 1989.

MORELlATO, L. P. C; BENCKE, C. S. C. Comparação de dois métodos de avaliação da fenologia de plantas, sua interpretação e representação. R. Bras. Bot., v. 25, n. 3 , p. 269-275, 2002.

PEDRALLI, G. Macrófitas aquáticas como bioindicadoras da qualidade de água: alternativas para usos múltiplos de reservatórios. In: THOMAZ, S. M.; BINI, L. M. (Eds.). Ecologia e manejo de macrófitas aquáticas. Maringá: Universidade Estadual de Maringá, 2003. p. 171-188.

PEDRALLI, G.; MEYER, S. T. Levantamento da vegetação aquática ("macrófitas") a das florestas de galeria na área da Usina Hidrelétrica de Nova Ponte, Minas Gerais. Bios, v. 4, n. 4, p. 49-60, 1996.
PEDRALLI, G.; TEIXEIRA, M. C. B. Macrófitas aquáticas como agentes filtradores de materiais particulados, sedimentos e nutrientes. In: HENRY, R. Ecótonos nas interfaces dos ecossitemas aquáticos. São Carlos: Rima, 2003. p. $177-194$.

PIO CORRÊA, M. Dicionário das plantas úteis do Brasil e das exóticas cultivadas. Rio de Janeiro: Instituto Brasileiro de Desenvolvimento Florestal, 1984. v. 6.

PITELLI, R. Macrófitas aquáticas no Brasil, na condição de problemáticas. In: WORKSHOP CONTROLE DE PLANTAS AQUÁTICAS, 1998, Brasília. Anais... Brasília: IBAMA, 1998. p. 12-15.

RAMSAR, COP7 DOC.24. Invasive Species and wetlands. The Ramsar Convention on Wetlands. Backgraund document: 12/01/01. Disponível em: <www.ramsar.org/cop7_doc_24_e.html>. Acesso em: 15 Dez. 2004. p. 1-7.

RAMSAR. Ramsar Information Paper no. 1. The Ramsar Convention Bureau, Rue Mauverney 28, CH-1196, 1971. Gland, Switzerland. Disponível em: <http:// www.ramsar.org/about_infopack_1e.htm>. Acesso em: 15 dez. 2004.

RIZZINI, C. T. Tratado de fitogeografia do Brasil. 2.ed. Rio de Janeiro: Âmbito Cultural Edições, 1997. 747 p.

SILVA, I. J. O.; NÄÄS, I. A. Efeito do sombreamento natural na redução da carga térmica de radiação. In: CONGRESSO BRASILEIRO DE ENGENHARIA AGRÍCOLA, 25., CONGRESSO LATINO AMERICANO DE INGENIERIA AGRÍCOLA, 2., 1996. Resumos... Sociedade Brasileira de Engenharia Agrícola, 1996. p. 428.

SMITH, C. W. Impacts of alien plants on Hawaii's native biota. In: STONE, C.P.; SCOTT, J.M. (Eds.) Hawaii's terrestrial ecosystems: preservation and management. Honolulu: University of Hawaii Cooperative National Park Resources Study Unit, 1985. p. 180-250.

STONE, C. P.; SMITH, C.W.; TUNISON, J.T. (Eds). Alien plant invasions in native ecosystems of Hawaii: management and research. Honolulu: University of Hawaii, Cooperative National Park Resources Study Unit, 1992. p. 887.

TUNISON, T. Element Stewardship Abstracts. The Nature conservancy. Virginia. Disponível em: $<$ http:// tncweeds.ucdavis.edu/esadocs/documnts/ hedycor.html $>$. Acesso em: 08 jun. 2003.

WONG, C. C. Shade tolerance of tropical forages. In: SHELTON, H.M.; STÜR, W.W. (Eds.) Forages for plantation crops. Camberra: ACIAR, 1991. p. 64-69. 